\title{
Applying a Robust Design Approach to Improve Online Systems Engineering Education
}

\author{
Alice Squires \\ School of Systems and Enterprises \\ Stevens Institute of Technology \\ Hoboken, NJ 07030
}

\author{
Robert Cloutier \\ School of Systems and Enterprises \\ Stevens Institute of Technology \\ Hoboken, NJ 07030
}

\begin{abstract}
The goal of robust design is to develop a system that performs optimally under a broad range of varying conditions including environmental conditions. A robust design is one that seeks to perform the ideal function while being insensitive to variations in environmental noise - uncontrollable factors that exist outside of the system, yet impact the ability of the system to perform the ideal function. This paper introduces a robust design framework for online systems engineering education and demonstrates its use. Combining observation and experimental design concepts, the framework is applied to the challenge of improving online course design by investigating the impact of the pedagogy used to deliver course lectures and discuss course content on student satisfaction and learning. The goal is to identify an approach for optimizing the student's learning experience and their development of system engineering competency knowledge by analyzing the student's self-perceived gain in competency knowledge related to system concepts and architectures, in a context where the students' age and years of systems engineering experience vary.
\end{abstract}

Keywords-systems engineering education; systems engineering graduate curriculum; robust design; systems engineering workforce development; systems engineering competencies

\section{INTRODUCTION}

By their very nature, educational systems are complex. The system complexity increases when educational systems extend beyond local boundaries of space and time, leveraging technology and the Internet to deliver education content to remote students. Given the short history of online education, remote online courses can be considered 'experiments in education'. From this perspective the outcome of these 'experiments' can be observed and analyzed to create a higher quality online educational system design. Furthermore, it is extremely important to perform this assessment in the early stages of the online program development before design decisions have been cast in stone. Robust design, also known as quality engineering, offers a conceptual backdrop that can be used to assess the 'experiments' being performed in the delivery of remote online systems engineering education and to build quality into the up front design of the system, going forward.

This paper introduces a robust design framework for observing and analyzing remote online systems engineering education. The intent of using a robust design approach for assessing remote online education is to simultaneously address minimizing sensitivity of the remote online systems engineering course design and delivery to a range of different types of students, instructors, space (location) and time (delay) constraints while optimizing the student's learning experience and outcome. This paper applies a robust design approach for identifying a set of course lecture and discussion delivery approaches that may potentially optimize the ability of a broad range of students to develop systems engineering competency knowledge in four competencies needed to support the development of system concepts and architecture (please see Appendix A for more detail). These four competencies are:

- $\quad$ form mission needs statement

- describe system environments

- $\quad$ perform trade studies

- $\quad$ create system architectures

The observed 'experiments' apply different methods of course lecture and discussion delivery in remote online courses where the students consist of both women and men, ranging from 20 to 60 years in age, with from zero to 15 years of systems engineering experience. The analysis demonstrates the feasibility of applying a robust design approach to online course design.

\section{BACKGROUND}

A robust design approach seeks to minimize sensitivity of the design to raw material, manufacturing, and operational variation while optimizing the quality, cost, and performance of the final product $[1,2,3]$.

According to [1], robustness is defined as: "the state where the technology, product, or process performance is minimally sensitive to factors causing variability... at the lowest ... cost" [1, p. 4]. In robust design, robustness is measured using a Signal to Noise $(\mathrm{S} / \mathrm{N})$ ratio that is defined by the energy transformed by the system to perform the intended function divided by the energy transformed by the system to perform unintended function. In Taguchi's words, robustness "measures the quality of energy transformation that occurs within a design... The higher the ratio, the higher the quality" [1, p. 7].

Therefore, the first goal of the robust design process is to make the product insensitive to variation. The second goal is to make the product's performance as close to the ideal performance as feasible within a reasonable cost. System optimization, therefore, requires a two-step process. First the design is evaluated, through experiments, for functional 
variability. The first goal is to reduce variability. Next, the average response (called sensitivity) must also be adjusted to achieve, as nearly as possible, the desired outcome. The second goal is the calibration of the output to the target value. In robust design, one addresses variability first, and then adjusts the sensitivity, in order to optimize the system design for the ideal outcome. Taguchi reminds us: "It is more effective to conduct experimentation at the upstream stage when fewer factors have been decided upon, and design changes are less expensive" [1, p. 8]. Ultimately, the goal of robust design is to optimize performance, cost and quality, at once, in the front end of the design cycle. Given that online education is early in its life cycle, now is the right time to evaluate remote online system engineering education by leveraging a robust engineering approach.

\section{A. Paremeter Diagram}

The Parameter Diagram (P-Diagram) introduced by [2] is one way to illustrate the initial planning phases for a robust system design approach. Please reference Figure 1 for a review of the characteristics of this diagram. First, the signal factors that form the primary inputs to the process transformation are defined and shown as entering the system of interest from the left hand side of the P-Diagram. As Phadke explains, these inputs are used "to express the intended value for the response of the product" [2, p. 31]. The response is the outcome of interest, also referred to as the 'quality characteristic', and is shown leaving the system of interest on the right. The parameters that cannot be controlled by the system designer are called noise factors, and enter from the top. The parameters that can be controlled by the system designer are called control factors, and enter from the bottom. The goal is to optimize the system for the ideal function, which uses the inputs on the left to create the response output on the right, and performs under conditions that can (control factors) or cannot (noise factors) be controlled.

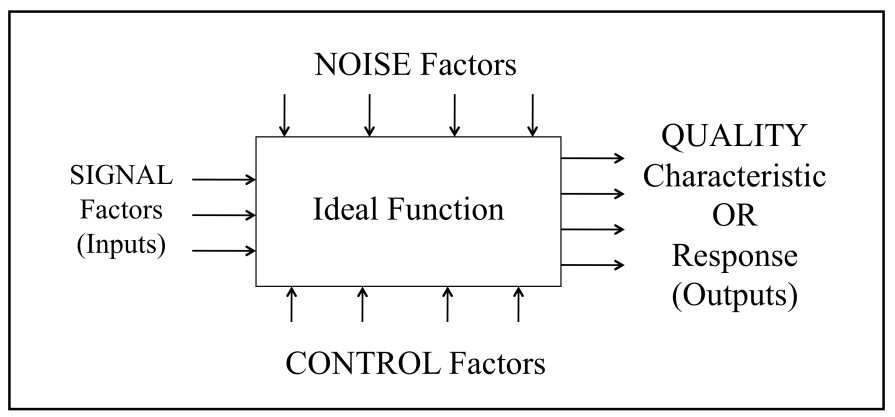

Figure 1. The Parameter Diagram (P-Diagram)

\section{B. Example I: Boeing 777 Design}

As an example, Figure 2 shows a possible P-Diagram for the design of the Boeing 777, based on [4]. In this example, the quality characteristic under investigation is the overall safety of the Boeing 777, given a certain number of passengers and the range of the flight. The designer has identified what she perceives as the critical factors that she has control over in the design stage. These control factors are the plane's shape and how the shape changes during takeoff, flight and landing; the type and number of engines; the overall weight of the plane, and the feedback between the plane's subsystems including the pilot. Those factors that the designer has no control over are the air pressure, the speed of the plane, the temperature, and who will fly the plane. While actual experiments will not be performed the designer can use two methods to gather data for her robust design approach. First, she can use actual data available from historical designs and flights; second she can use modeling techniques. In each case she would use the twopass optimization approach to evaluate the impact of changing various control factors under various environmental conditions when flying under certain passenger loads for a given range, on overall safety.

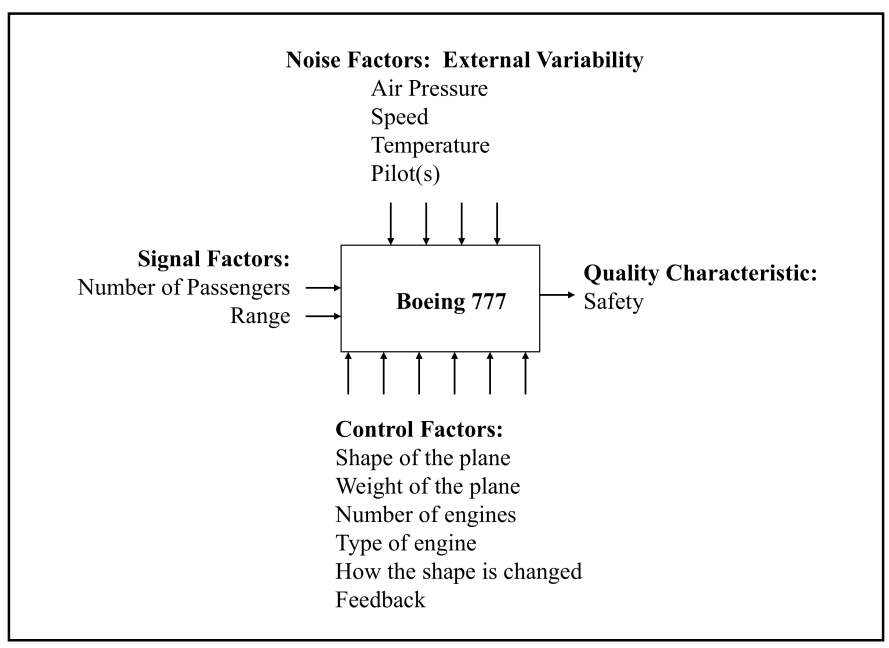

Figure 2. Example P-Diagram for the Boeing 777 Design

\section{LITERATURE REVIEW}

Examples of alternative distance education frameworks used for assessing online communities and distance education are reviewed in this section. These frameworks are summarized in Table 1 and described in more detail in the following sections.

TABLE I. EXAMPLES OF Alternative Distance EDUCATION EVALUATION FRAMEWORKS ${ }^{\mathrm{a}}$

\begin{tabular}{|c|l|}
\hline \multicolumn{1}{|c|}{ Framework } & \multicolumn{1}{|c|}{ Description } \\
\hline Community of Inquiry & $\begin{array}{l}\text { An instrument for measuring social presence, } \\
\text { teaching presence and cognitive presence in } \\
\text { computer mediated conferences. }\end{array}$ \\
\hline $\begin{array}{c}\text { Learner Interactions } \\
\text { Model }\end{array}$ & $\begin{array}{l}\text { A straightforward model focused on learner- } \\
\text { content, learner-instructor, learner-learner and } \\
\text { learner-interface interactions. }\end{array}$ \\
\hline $\begin{array}{c}\text { Interaction Analysis } \\
\text { Model }\end{array}$ & $\begin{array}{l}\text { A phased model that groups analysis of } \\
\text { computer mediated conferencing interaction } \\
\text { into sequential knowledge development } \\
\text { phases leading to newly constructed meaning. }\end{array}$ \\
\hline The Unfolding Model & $\begin{array}{l}\text { A broad multi-faceted model that combines } \\
\text { scientific quantitative approaches and } \\
\text { qualitative research methods resulting in } \\
\text { multiple perspectives for evaluating processes } \\
\text { and outcomes in distance education. }\end{array}$ \\
\hline
\end{tabular}

a. Based on literature research completed as part of Squires' doctoral dissertation [17] 


\section{A. Community of Inquiry}

The Community of Inquiry instrument was originally developed by [5]. This instrument measures teacher presence, social presence, and cognitive presence in computer-mediated conferences. The instrument has been used to evaluate online transcripts to research a broad list of areas including the following examples related to developing a sense of online community:

- the relationship between developing a sense of community in an online course and online course drop out rate [6],

- a comparison of the development of community between online and blended courses [7];

- an evaluation of factors for building a sense of community [8];

Researchers have collaborated to validate the Community of Inquiry instrument [9, 10, 11].

\section{B. Learner Interactions Model}

Moore (1989) defined three types of interaction in the online environment: learner-content, learner-instructor, learnerlearner and describes them as follows [12]:

- Learner-content interaction describes the interaction of the learner to the content or subject that is being studied.

- Learner-instructor interaction is defined as the interaction between the learner and the 'expert'.

- Learner-learner interaction is the interaction between the learners, with or without the instructor being present.

Hillman, Willis \& Gunawardena (1994) suggested a fourth type of interaction - learner-interface - which includes the interaction of the learner with the tools needed to perform the learning task [13].

\section{Interaction Analysis Model}

Gunawardena, Lowe \& Anderson (1997) continued the work on interaction models and suggested an Interaction Analysis Model for Examining Social Construction of Knowledge that grouped interactions in computer mediated conferences into sequential phases. These phases are [14]:

- Phase I: Sharing/Comparing of Information

- $\quad$ Phase II: Discovery of dissonance and inconsistency

- $\quad$ Phase III: Negotiation of Meaning/Co-construction of knowledge

- Phase IV: Testing and modification of proposed synthesis

- $\quad$ Phase V: Agreement/application of newly constructed meaning

However, when performing a transcript analysis, the same team found that over $88 \%$ of the postings fell into Phase I, thereby questioning the usefulness of the model [14].

\section{The Unfolding Model}

The Unfolding Model for Evaluation suggested by [15] is based on Messick's (1989) framework on validity [16]. Messick's framework is based on the idea of building a 'case' about the worth or merit of the object under assessment that is not based strictly on the scientific method [16]. In support of this approach, the Ruhe and Zumbo (2009) Unfolding Model for distance education evaluation is based on 1) science and 2) impact or consequence. These two areas are further defined as follows [15]:

1. Scientific basis:

- scientific evidence (examples: survey or grade outcomes)

- relevance (alignment, meaningfulness, learning transfer)

- $\quad \operatorname{cost} /$ benefit (to university and/or learners)

2. Consequential basis

- Underlying values (theories, goals, ideologies, etc...)

- Unintended Consequences (instructional, social, implementation, etc...)

The use of the model results in a mixed methods approach to research, covering all aspects of scientific quantitative approaches as well as qualitative research. As a result, the framework allows one to evaluate the processes and outcomes being used to deliver the distance education under study, through the lens of multiple perspectives.

\section{RESEARCH METHODOLOGY}

The research methodology presented here represents a subset of the approach used to complete research for Squires' doctoral dissertation [17].

\section{A. Design of the Experiment}

For this experiment, a robust design approach will be applied using the framework shown in Figure 3.

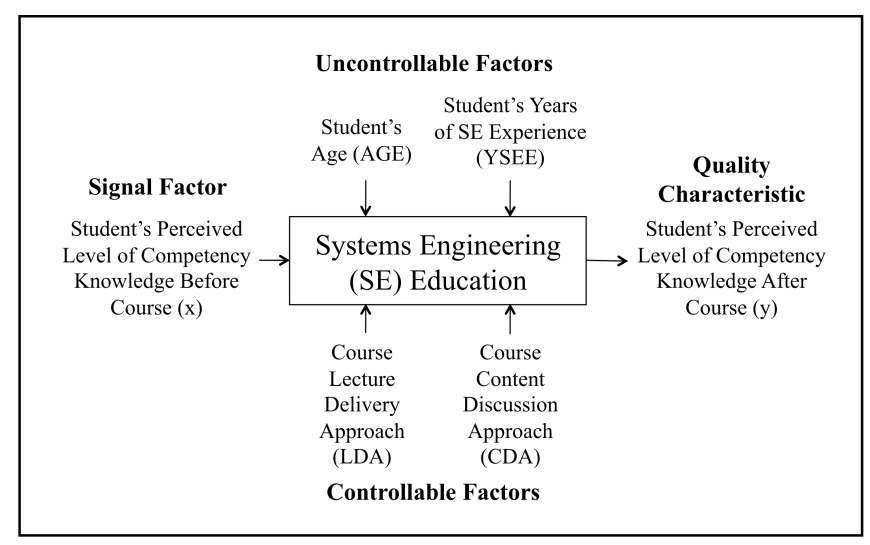

Figure 3. Experimental Approach

The robust design approach requires an analysis of variability (first) and then sensitivity/tuning (second) in order 
to fine-tune the control factors to obtain optimal performance with least variability in performance in the environment in which the system must perform. While the intent of robust engineering is to design and run experiments to achieve the data necessary early in the design cycle, the research reported in this paper is based on a summary of online 'experiments' that have already taken place in a naturalistic setting. As Deming [18] suggests:

\begin{abstract}
...it is not always necessary to perform experimentation to accumulate data for understanding and improving the process... My friend Dr. E. E. Nishibori of Tokyo first mentioned to me the economy and efficiency of making observations on natural variation, leaving experimentation for problems not solved by simple observation. In other words,... make use of existing information [18, pp. 391-392].
\end{abstract}

\section{1) Ideal Function}

For our experiment, the ideal outcome (y) is that the student will achieve the maximum of (the starting level of competency knowledge, the desired level of competency knowledge) where the starting level is the level of competency knowledge the student has before starting the course (x) and the desired level of competency knowledge is the target level the student should achieve upon completing the course. This can be expressed as:

$$
\text { Ideal } y=\operatorname{MAX}(\mathrm{x}, \text { target })
$$

The target value is defined by the values that represent the instructors' perceptions of the level of competency knowledge each student should achieve in each competency, upon successful completion of their course.

Input (x)/output (y) values are the before/after values that the students assign to their competency knowledge level based on the following scale:

- 0 - Little to No knowledge

- 1 - Basic level

- 2 - Between Basic and Intermediate

- 3 - Intermediate level

- 4 - Between Intermediate and Expert

- 5 - Expert knowledge

Where basic, intermediate and expert are defined as follows:

- Basic: able to understand a discussion about and follow directions related to the competency.

- Intermediate: comfortable making decisions about and leading discussions related to the competency.

- Expert: many others look to you for knowledge about the competency.

\section{2) Signal to Noise Ratio (Variability)}

The signal to noise $(\mathrm{S} / \mathrm{N})$ ratio in robust design represents the ratio of energy transformed to perform the intended function to energy transformed to other than the intended function where the intended function is the ideal function. For our purposes, the $\mathrm{S} / \mathrm{N}$ value ideally ranges from 0 to 1 such that $\mathrm{S} / \mathrm{N}=0$ represents no energy has been transformed into the intended function $(\mathrm{y}=0)$ and $\mathrm{S} / \mathrm{N}=1$ represents the intended function has been performed ( $\mathrm{y}>=$ Ideal $\mathrm{y})$. However, if the student has achieved a higher level than when they started that also exceeds the target level set by the instructor, then $\mathrm{S} / \mathrm{N}$ can be greater than 1 . The closer the $\mathrm{S} / \mathrm{N}$ is to 1 , the more energy has been transformed into the intended function of the system; when $\mathrm{S} / \mathrm{N}$ is greater than 1, that means either the target was set too low, the student is not accurately assessing their current level, or there is external energy acting upon the system that has not been taken into account. Assuming a linear relationship, the equation used to calculate $\mathrm{S} / \mathrm{N}$ is:

$$
\mathrm{S} / \mathrm{N}=\mathrm{y} / \text { Ideal } \mathrm{y}
$$

In our case, the higher the $\mathrm{S} / \mathrm{N}$ value, the higher the student perceived level of competency knowledge after successfully completing the course therefore, we are looking for the maximizing $\mathrm{S} / \mathrm{N}$ value.

\section{3) Sensitivity}

In robust design, sensitivity refers to the ability to adjust the response to be as close as possible to the intended target value, in this case Ideal y. Assuming that the more satisfied student will be less sensitive to variability in achieving the intended target value, we will use student satisfaction to measure sensitivity in our system. In the remote online environment, it is important to look at two types: 1) student satisfaction with the course and 2) student satisfaction with the instructor [19, $20,21,22]$. For our purposes, the sensitivity measure will range from 0.2 to 1 and be defined as follows:

\section{Sensitivity $=2 /($ SSCourse + SSInstructor $)$}

Where SSCourse $=$ the student's satisfaction with the course and SSInstructor $=$ the student's satisfaction with the instructor. Each are selected, respectively, according to the student's level of agreement to the following two statements:

- The instructor was an effective teacher.

- This was an excellent course.

and values are assigned as follows:

- $\quad$ Strongly Agree $=5$

- $\quad$ Agree $=4$

- $\quad$ Neither Agree or Disagree $=3$

- $\quad$ Disagree $=2$

- $\quad$ Strongly Disagree $=1$

In our case, the lower the sensitivity value, the more satisfied the student; therefore, we are looking for the minimizing sensitivity value.

\section{4) Controllable (Control) Factors}

In robust engineering control factors represent design decision points. We use the term controllable factors to distinguish the instructor's course delivery decisions from those factors the instructor cannot typically control in the delivery of the course, such as student characteristics or university policy. For this analysis, the controllable factors being considered are the course lecture delivery approach (LDA) and the course content discussion approach (CDA). In the sample set used for this analysis, all of the online courses 
have weekly lectures that are provided in the form of a posted slide deck. However, some instructors provide additional lecture material in the form of live or recorded weekly lectures or by providing slide decks annotated with the weekly lectures in the speaker notes. Similarly, for course content discussions instructors may have no form of discussion in the course, or they may provide weekly text based discussions, or, finally, they may hold weekly live discussions or provide audio recorded discussions. The different levels that will be used for these two factors are shown in Table II where the assumption is that the material is being delivered on a weekly basis in over half the number of weeks of the length of the course, which for this sample set is thirteen weeks of class, one week of finals.

TABLE II. CONTROLLABLE FACTORS: 2 FACTORS, 3 LEVELS EACH

\begin{tabular}{|c|c|c|c|}
\hline $\begin{array}{c}\text { Controllable } \\
\text { Factors } \\
\end{array}$ & Level 1 & Level 2 & Level 3 \\
\hline $\begin{array}{l}\text { Lecture } \\
\text { Delivery } \\
\text { Approach } \\
(L D A)\end{array}$ & $\begin{array}{l}\text { slides, can have } \\
\text { multimedia but } \\
\text { no speaker } \\
\text { notes or audio } \\
\text { lectures }\end{array}$ & $\begin{array}{l}\text { slides that } \\
\text { include written } \\
\text { text of lecture } \\
\text { such as through } \\
\text { speaker notes. }\end{array}$ & $\begin{array}{l}\text { slides with } \\
\text { instructor } \\
\text { recorded or } \\
\text { instructor live } \\
\text { audio }\end{array}$ \\
\hline $\begin{array}{l}\text { Content } \\
\text { Discussion } \\
\text { Approach } \\
\text { (CDA) }\end{array}$ & $\begin{array}{c}\text { no course } \\
\text { content } \\
\text { discussions in } \\
\text { class }\end{array}$ & $\begin{array}{l}\text { text based } \\
\text { discussions }\end{array}$ & $\begin{array}{l}\text { instructor } \\
\text { recorded or } \\
\text { instructor live } \\
\text { discussions }\end{array}$ \\
\hline
\end{tabular}

\section{5) Uncontrollable (Noise) Factors}

For this analysis we chose to use factors that we did not have control over as the noise factors; these represent various conditions that the system has to operate under. We selected student age (AGE) and numbers of years of student's experience specific to systems engineering (YSE) as two important influencing but 'uncontrollable' factors. The different levels that will be used for these two factors are shown in Table III.

TABLE III. UNCONTROLLABLE FACTORS: 1 FACTOR, 2 LEVELS; 1 FACTOR, 3 LEVELS

\begin{tabular}{|c|c|c|c|}
\hline Uncontrollable Factors & Level 1 & Level 2 & Level 3 \\
\hline Student Age (AGE) & $\begin{array}{c}<=30 \\
\text { years }\end{array}$ & $\begin{array}{c}>30 \\
\text { years }\end{array}$ & -- \\
\hline $\begin{array}{c}\text { Years of student's experience in } \\
\text { systems engineering (YSE) }\end{array}$ & 0 years & $\begin{array}{c}>0 \text { to 5 } \\
\text { years }\end{array}$ & $\begin{array}{c}>5 \\
\text { years }\end{array}$ \\
\hline
\end{tabular}

\section{B. Data Collection Methods and Return Rates}

The data collection methods used for the research reviewed in this paper consisted of 1) an in-depth analysis of 27 online systems engineering and related classes delivered in the Spring 2010 term, and 2) distribution and collection of data from instructor and student surveys. The online classroom analyses focused on evidence of the methods the instructors used to deliver course lectures and discuss course content. This data was used to understand and validate the results from the surveys. The surveys were distributed and data collected electronically.
The instructor survey collected data on:

- Instructor's course lecture and content discussion pedagogy used to deliver course material to student

- Instructor perception of systems engineering competencies covered in class

- Instructor perception of level of competency knowledge addressed for each competency covered

Data was collected from $100 \%$ of the 21 instructors involved (in some cases an instructor taught more than one course type or more than one section of the same course, delivering a total of 27 online classes).

The student survey collected data on:

- Student number of years of professional and systems engineering experience

- Student perception of instructor's course lecture and content discussion pedagogy

- Student satisfaction with course and instructor

- Student perception of systems engineering competencies covered in class

- Student perceived personal level of competency knowledge growth for each competency covered

- $\quad$ Optional] Age range (5 year ranges) and gender

Data was collected from $25 \%$ of the 422 student enrollments (348 students enrolled in one or more courses).

\section{Obstacles}

One important obstacle to the research was a difference in instructor and student perceptions of which competencies were addressed in the course. This threat to validity is addressed separately in [17] and [23]. For the analysis reviewed in this paper, only responses where both the instructor and student in the same course agreed on whether or not the competency was covered in the course, were used to run the analysis.

A second key challenge was the fact that although an instructor used a certain set of online pedagogy to offer a certain learning experience to the remote students, it was a choice of the student as to whether he or she took full advantage of what was offered. However, for purposes of this paper and the demonstration of the robust design approach, the online pedagogy offered by the instructor is used for the control factors and the student's level of use of the online pedagogy provided is one of several confounding factors noted.

Secondary obstacles to the research included other threats to validity such as sample bias, differences in technology availability and performance, instructor and student bias, etc.; and other confounding factors such as instructor teaching style, instructor and student learning styles, differing social aspects of the online interactions, degree of personally meaningful content, student experiences outside the classroom during the timeframe evaluated, etc. However, the approach demonstrated focuses on differences in the student's age and systems engineering experience (in number of years) as the uncontrollable factors involved. In general, the approach demonstrated in this paper was heretofore presented as 
theoretical [24] and this paper demonstrates the use of actual data in the application of a robust design approach using the suggested framework.

\section{FINDINGS}

While robust design typically recommends the use of an orthogonal array to set up the required number of experiments to carry out the process, in this case, the experiments have already been run and it's a matter of organizing the results into a proper representation of 'runs' based on robust design principles and then applying the robust design process. For this analysis, 67 student enrollment responses across 17 classes (13 courses, 14 instructors) met the conditions where both instructor and student agree that one or more of the competencies under consideration are covered in course, resulting in a total of 118 data samples. Each data sample is considered an individual experiment or 'run' in robust design terminology.

The findings from the 118 runs are summarized in the following sections.

\section{A. Sample Distribution by Controllable Factor}

For each class delivered, the instructor used a particular approach for delivering course lectures and discussing course content. For the levels of each controllable factor, the number of classes, student responses, and the resulting number of data samples ('runs' for our experiment) are shown in Table IV.

TABLE IV. CONTROLLABLE FACTORS: 'RUNS' FOR EACH

\begin{tabular}{|c|c|c|c|c|c|}
\hline \multicolumn{2}{|c|}{ Controllable Factors } & \multirow{2}{*}{$\begin{array}{c}\text { Level } 1 \\
4\end{array}$} & \multirow{2}{*}{$\begin{array}{c}\text { Level } 2 \\
2\end{array}$} & \multirow{2}{*}{$\begin{array}{c}\text { Level } 3 \\
10\end{array}$} & \multirow{2}{*}{$\begin{array}{c}\begin{array}{c}\text { Levels } \\
\mathbf{2} \boldsymbol{\&} \mathbf{3}^{\mathbf{b}}\end{array} \\
1\end{array}$} \\
\hline Lecture & \# classes & & & & \\
\hline $\begin{array}{c}\text { Delivery } \\
\text { Approach }\end{array}$ & \# students & 16 & 9 & 40 & 2 \\
\hline$(L D A)$ & \# data samples & 29 & 14 & 71 & 4 \\
\hline \multirow{3}{*}{$\begin{array}{c}\text { Content } \\
\text { Discussion } \\
\text { Approach } \\
\text { (CDA) }\end{array}$} & \# classes & $0^{\mathrm{c}}$ & 15 & 1 & 1 \\
\hline & \# students & $0^{\mathrm{c}}$ & 54 & 6 & 7 \\
\hline & \# data samples & $0^{\mathrm{c}}$ & 105 & 6 & 7 \\
\hline
\end{tabular}

b. One class in each factor category delivered course content using two of the three approaches.

c. While four of the original 27 classes had no form of discussion in the class, the student response rates for these classes was low, covering $0,1,2$ and 4 responses in each of the four classes, and only two students identified one or more of the four competencies as covered in the course and in those situations the instructor did not agree. For this reason, no sample data fell into the Level 1 CDA category.

As shown, the primary approaches used to deliver course content in the online classes in this sample set were through live/recorded audio lectures and text based discussions (bolded columns).

\section{B. Experimental 'Runs'}

Table V shows the sample data categorized by controllable factor pairings, noting the uncontrollable factors that apply to each 'run'. As shown, with this sample set, courses with lecture slides that were either annotated with the lecture text in the speaker notes or included recorded/live audio were not paired with recorded or live course content discussions (see bolded rows). Also, there were no cases where the student had both more than five years of systems engineering experience and was under the age of 30 (see bolded column).

TABLE V. EXPERIMENTAL 'RUNS' (NATURALISTIC SETTING)

\begin{tabular}{|c|c|c|c|c|c|c|c|c|}
\hline \multirow[b]{2}{*}{$\begin{array}{c}\text { LDA } \\
\text { Level }\end{array}$} & \multirow[b]{2}{*}{$\begin{array}{c}\text { CDA } \\
\text { Level }\end{array}$} & \multicolumn{2}{|c|}{ YSE $=0$} & \multicolumn{2}{|c|}{ YSE $>0$ to 5} & \multicolumn{2}{|c|}{ YSE $>5$} & \multirow[b]{2}{*}{$\begin{array}{c}\text { Total } \\
\text { 'Runs' } \\
\end{array}$} \\
\hline & & $\begin{array}{l}\text { AGE } \\
<=30\end{array}$ & $\begin{array}{c}\text { AGE } \\
>\mathbf{3 0}\end{array}$ & $\begin{array}{l}\text { AGE } \\
<=30\end{array}$ & $\begin{array}{c}\text { AGE } \\
>\mathbf{3 0}\end{array}$ & $\begin{array}{l}\text { AGE } \\
<=30\end{array}$ & $\begin{array}{c}\text { AGE } \\
>\mathbf{3 0}\end{array}$ & \\
\hline $\mathrm{x}$ & 1 & 0 & 0 & 0 & 0 & 0 & 0 & 0 \\
\hline 1 & 2 & 2 & 2 & 3 & 9 & $\mathbf{0}$ & 7 & 23 \\
\hline 1 & 3 & 0 & 2 & 0 & 2 & 0 & 2 & 6 \\
\hline 2 & 2 & 1 & 1 & 2 & 8 & 0 & 2 & 14 \\
\hline 2 & 3 & 0 & $\mathbf{0}$ & 0 & 0 & 0 & 0 & 0 \\
\hline 3 & 2 & 20 & 6 & 14 & 10 & $\mathbf{0}$ & 14 & 64 \\
\hline 3 & 3 & $\mathbf{0}$ & 0 & $\mathbf{0}$ & $\mathbf{0}$ & $\mathbf{0}$ & $\mathbf{0}$ & 0 \\
\hline 3 & 2,3 & 3 & 0 & 1 & 0 & $\mathbf{0}$ & 3 & 7 \\
\hline 2,3 & 2 & 0 & 0 & 2 & 2 & $\mathbf{0}$ & 0 & 4 \\
\hline & & & & & & & & 118 \\
\hline
\end{tabular}

\section{S/N and Sensitivity Calculations and Plots}

Next, individual and overall $\mathrm{S} / \mathrm{N}$ and sensitivities are calculated for each experimental run and averaged as shown in Tables VI through IX. Plots of the results from Tables VI through IX are shown in Figures 4 and 5.

TABLE VI. LDA S/N RESULTS

\begin{tabular}{|c|c|c|c|}
\hline LDA S/N & $\begin{array}{c}\text { Total } \\
\text { S/N }\end{array}$ & $\begin{array}{c}\text { Number } \\
\text { of Runs }\end{array}$ & $\begin{array}{c}\text { Average } \\
\text { S/N }\end{array}$ \\
\hline LDA1 & 36.33 & 29 & 1.25 \\
\hline LDA2 & 16.42 & 14 & 1.17 \\
\hline LDA3 & 79.47 & 71 & 1.12 \\
\hline LDA2,3 & 5.67 & 4 & 1.42 \\
\hline Total & 137.88 & 118 & 1.17 \\
\hline
\end{tabular}

TABLE VII. CDA S/N RESULTS

\begin{tabular}{|c|c|c|c|}
\hline CDA S/N & $\begin{array}{c}\text { Total } \\
\text { S/N }\end{array}$ & $\begin{array}{c}\text { Number } \\
\text { of Runs }\end{array}$ & $\begin{array}{c}\text { Average } \\
\text { S/N }\end{array}$ \\
\hline CDA2 & 117.30 & 105 & 1.12 \\
\hline CDA3 & 7.83 & 6 & 1.31 \\
\hline CDA2,3 & 12.75 & 7 & 1.82 \\
\hline Total & 137.88 & 118 & 1.17 \\
\hline
\end{tabular}

TABLE VIII. LDA SENSITIVITY RESULTS

\begin{tabular}{|c|c|c|c|}
\hline $\begin{array}{c}\text { LDA } \\
\text { Sensitivity }\end{array}$ & $\begin{array}{c}\text { Total } \\
\text { Sensitivity }\end{array}$ & $\begin{array}{c}\text { Number } \\
\text { of Runs }\end{array}$ & $\begin{array}{c}\text { Average } \\
\text { Sensitivity }\end{array}$ \\
\hline LDA1 & 6.91 & 29 & 0.24 \\
\hline LDA2 & 3.62 & 14 & 0.26 \\
\hline LDA3 & 15.88 & 71 & 0.22 \\
\hline LDA2,3 & 0.80 & 4 & 0.20 \\
\hline Total & 27.21 & 118 & 0.23 \\
\hline
\end{tabular}


TABLE IX. CDA SENSITIVITY RESULTS

\begin{tabular}{|c|c|c|c|}
\hline $\begin{array}{c}\text { CDA } \\
\text { Sensitivity }\end{array}$ & $\begin{array}{c}\text { Total } \\
\text { Sensitivity }\end{array}$ & $\begin{array}{c}\text { Number } \\
\text { of Runs }\end{array}$ & $\begin{array}{c}\text { Average } \\
\text { Sensitivity }\end{array}$ \\
\hline CDA2 & 23.73 & 105 & 0.23 \\
\hline CDA3 & 1.74 & 6 & 0.29 \\
\hline CDA2,3 & 1.74 & 7 & 0.25 \\
\hline Total & 27.21 & 118 & 0.23 \\
\hline
\end{tabular}
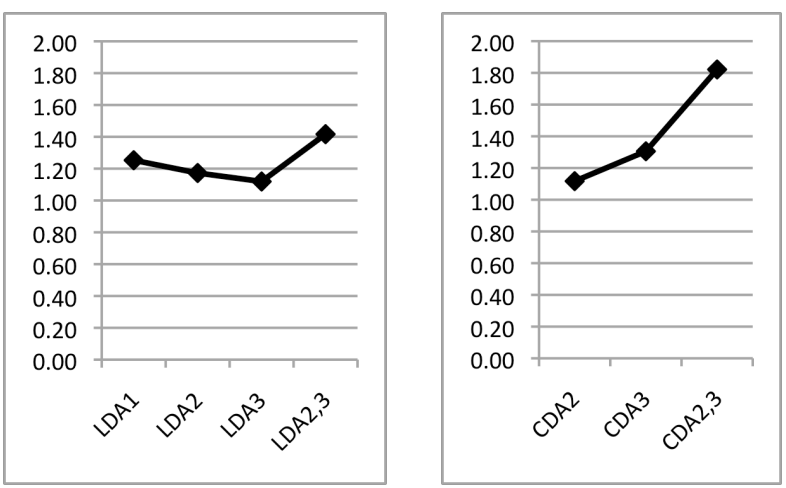

Figure 4. S/N Plots
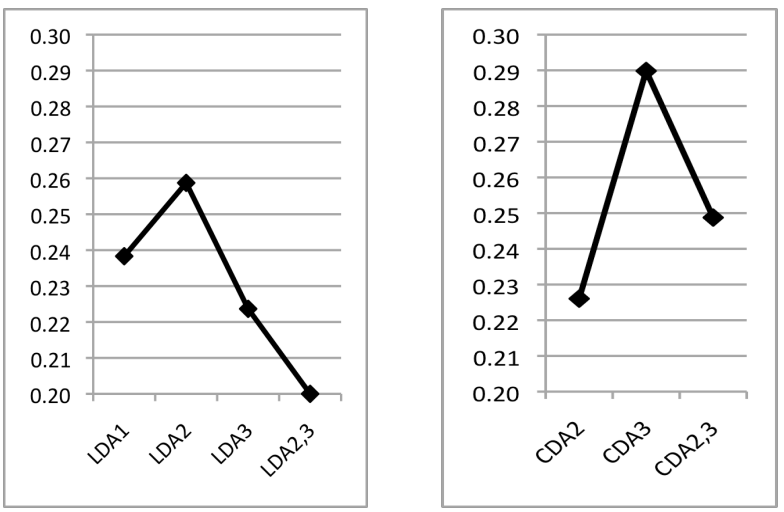

Figure 5. Sensitivity Plots

As shown, in Figure 4, the average $\mathrm{S} / \mathrm{N}$ value was greater than one for each factor. As previously noted, this implies that either the instructor taught the competency at a level higher than anticipated, the student estimated their knowledge level as higher than actual, or there was external energy from outside the system (such as on the job experience) that allowed the student to surpass the intended level of learning. Additional analysis would be needed to determine the actual cause(s). The Figure 4 plots indicate that the course delivery approach has the greatest potential for positively impacting learning. The most efficient method appears to be a combination of course discussion both online and through recorded/live audio. However, one caution is the small amount of data used to support the CDA3 and CDA2,3 results. In addition, the cost of this approach would have to be weighed against the benefits. The Figure 5 plots indicate that the combined recorded/live audio lecture with speaker notes of the lecture posted in the classroom lecture delivery approach (LDA2,3) provides the minimum possible level of sensitivity, which is desired. However, once again, only a small amount of data is used to support the LDA2,3 results and the cost of this approach would have to be weighed against the benefits.

These results indicate that in the online environment, the approach used to deliver lectures may be used to reduce student sensitivity by increasing the level of student satisfaction with the course and the instructor. The approach that appears to have the most promise based on this analysis is the combination of using recorded or live lectures combined with providing a copy of all the slides with speaker notes of the lecture incorporated. The approach used to discuss course content has promise as a driving factor for learning where the most promising approach appears to be a combination of online text-based and real-time discussions of course content. One likely explanation is that using both text-based and audio-based approaches may better address the diversity of student learning styles. However, further analysis would need to be performed in this area to ascertain the cause of the findings.

\section{FUTURE RESEARCH}

This analysis only used two controllable factors, but there are many other factors that could be included such as class size or level of faculty participation and feedback. Also, there are other external factors such as student gender, total years of experience, and learning styles. And finally, only four competencies were included in the analysis but the systems engineering competency model used addresses 37 competencies; all 37 could be included in the analysis. These are potential areas for follow-on research.

\section{CONCLUSION}

Effectively educating systems engineering students is challenging due to the experiential nature of systems engineering. The situation becomes even more challenging when that education is delivered from a distance - in both time and space. Such is the case with remote online systems engineering education. This paper offers a rigorous approach for observing and analyzing online course delivery outcomes of existing courses in order to identify improvements to course design and delivery over the long term. An example of applying a robust design approach is provided for two online course design factors: course lecture delivery and course content discussion. The analysis leverages actual data from students' ranging from 20 to 60 years old with from zero to 15 years of systems engineering experience and demonstrates the feasibility of applying a robust design approach to online course design. The results indicate that in the online environment, the approach used to deliver lectures may be used to reduce student sensitivity by increasing the level of student satisfaction with the course and the instructor, while the approach used to discuss course content has promise as a driving factor for learning. The intent is for this framework to be extensible going forward to other modalities of systems engineering education as well as related educational domains. 


\section{APPENDIX A. CONCEPTS AND ARCHITECTURE}

A full description of the competency model that forms the basis of this research is available in [25]. "Concepts and architecture" covers competency in understanding the mission need, the concept of operations, and the system environment and applying this understanding to the development of a viable and complete system architecture. The four competencies within this competency area are briefly defined as follows:

- Form mission needs statement: addresses the ability to accurately identify the mission need and the basis for that need.

- Describe system environments: includes a full understanding of the system environment and the inherent constraints and the ability to establish design guidance for the expected environment.

- Perform trade studies: are important for comparing and contrasting the identified viable system level technical solutions.

- Create system architectures: covers developing the various system architectural views and begins with establishing the proper bounds of the system and defining the external interfaces.

\section{REFERENCES}

[1] G. Taguchi, S. Chowdhury, and S. Taguchi. Robust Engineering. McGraw-Hill, 2000.

[2] M. S. Phadke, Quality Engineering Using Robust Design. 1st ed. Englewood Cliffs, New Jersey: Prentice Hall, 1989.

[3] W. Y. Fowlkes, and C. M. Creveling. Engineering Methods for Robust Product Design: Using Taguchi Methods in Technology and Product Development. Addison-Wesley Reading, MA, 1995.

[4] K. Sabbagh, 21st Century Jet: The Making and Marketing of the Boeing 777. Vol. 162. N.p.: Scribner, 1996.

[5] Garrison, D R, T Anderson, and W Archer. "Critical Thinking, Cognitive Presence, and Computer Conferencing in Distance Education." American Journal of Distance Education, vol. 15, no. 1, pp. 7-24, 2001.

[6] W. Boston, S. R. Diaz, A. Gibson, P. Ice, J. Richardson, and K. Swan. "An Exploration of the Relationship Between Indicators of the Community of Inquiry Framework and Retention." Journal of Asynchronous Learning Networks vol. 13, no. 3, pp. 67-83, 2009.

[7] Z. Akyol, D. R. Garrison, and M. Y. Ozden. "Development of a Community of Inquiry in Online and Blended Learning Contexts." Procedia - Social and Behavioral Sciences, vol. 1, no. 1 pp. 1834-1838, 2009.

[8] E. J. Stodel, T. L. Thompson, and C. J. MacDonald. "Learners'perspectives on What Is Missing From Online Learning: Interpretations Through the Community of Inquiry Framework." International Review of Research in Open and Distance Learning, vol. 7, no. 3, p. 24, 2006.

[9] P. Shea, and T. Bidjerano. "Community of Inquiry As a Theoretical Framework to Foster "Epistemic Engagement" and "Cognitive
Presence" in Online Education." Computers \& Education vol. 52, pp. 543-553, 2008.

[10] K. P. Swan, J. C. Richardson, P. Ice, D. R. Garrison, M. ClevelandInnes, and J. B. Arbaugh. "Validating a Measurement Tool of Presence in Online Communities of Inquiry." e-mentor, vol. 2, no. 24 pp. 1-12, 2008

[11] J. B. Arbaugh, "Does the Community of Inquiry Framework Predict Outcomes in Online MBA Courses?" International Review of Research in Open and Distance Learning, vol. 9, no. 2 p. 21, June, 2008.

[12] M.G. Moore. "Editorial: Three Types of Interaction." The American Journal of Distance Education, vol. 3, no. 2, pp. 1-6. 1989.

[13] D. C. A. Hillman, D. J. Willis, and C. N. Gunawardena. "LearnerInterface Interaction in Distance Education: An Extension of Contemporary Models and Strategies for Practitioners." American Journal of Distance Education, vol. 8, no. 2, pp. 30-42, 1994.

[14] C. N. Gunawardena, C. A. Lowe, and T. Anderson. "Analysis of a Global Online Debate and the Development of An Interaction Analysis Model for Examining Social Construction of Knowledge in Computer Conferencing." Journal of educational computing research, vol. 17, no. 4, pp. 397-431, 1997.

[15] V. Ruhe, and B. D. Zumbo. Evaluation in Distance Education and ELearning: The Unfolding Model. N.p.: The Guilford Press, 2009.

[16] Messick, S. "Validity." Educational measurement, vol. 3, no. 1, pp. 13103, 1989.

[17] A. Squires. "Investigating the Relationship Between Online Pedagogy and Student Competency Knowledge Development in Systems Engineeirng Education.” Thesis, Stevens Institute of Technology, School of Systems and Enterprises, 2011.

[18] W. E. Deming. Out of the Crisis. 3rd ed. The MIT Press, 2000 (originally published in 1982).

[19] DeBourgh, G A. "Predictors of student satisfaction in distance-delivered graduate nursing courses: What matters most?" Journal of Professional Nursing, vol. 19, iss. 3, pp. 149-163, 2003.

[20] G. M. Sabine. "A comparison of student learning and student satisfaction in an online distance education format and a traditional format in a technical college in georgia." Thesis, The University of Georgia, Athens, Georgia. 2005.

[21] A. Squires, and M. Pennotti. "Measuring the value of course components applied in the online classroom." Proceedings of the 2007 american society for engineering education (ASEE) annual conference and exposition, honolulu, hawaii, june 24-27, 2007.

[22] Chang, Shu-Hui Hsieh and Roger A Smith. 2008. "Effectiveness of personal interaction in a learner-centered paradigm distance education class based on student satisfaction." Journal of Research on Technology in Education, vol. 40, iss. 4, pp. 407-426, 2008.

[23] A. Squires, and R. Cloutier. (2011), "Comparing Perceptions of Competency Knowledge Development in Systems Engineering Curriculum: A Case Study", Proceedings of the 2011 american society for engineering education (ASEE) annual conference, Vancouver, BC, Canada, June 26-29, 2011.

[24] A. Squires, and R. Cloutier. "Developing a Strategy to Measure Systems Engineering Competency Knowledge Demonstrated in the Remote Asynchronous Online Classroom", $8^{\text {th }}$ Conference on Systems Engineering Research (CSER), Hoboken, NJ, March 17-19, 2010.

[25] A. Squires, W. Larson, and B. Sauser. "Mapping space-based systems engineering curriculum to government-industry vetted competencies for improved organizational performance." Systems Engineering, vol. 13, iss. 3 , pp. $246-260,2010$ 